\title{
0 olhar distanciado: o programa etnológico de Rousseau
}

The View From Afar: The Rousseau's Ethnological Program

\author{
Mauro Dela Bandera Arco Junior \\ Professor adjunto do Centro de Filosofia e Ciências Humanas \\ Universidade Federal do Acre [UFAC]
}

\section{RESUMO}

A exortação de Rousseau, feita dois séculos antes de Lévi-Strauss, de levar a vista ao longe, observar as diferenças entre os homens para conhecer o homem em sua especificidade e propriedade dá o tom do que se poderia chamar de antropologia rousseauísta. O conhecimento sobre o homem náo é obtido ao olhar para o lado e tomar como referência um tipo qualquer imediatamente disponível. Ao contrário, é preciso de viagens bem regradas, de uma educação do olhar e da organização dos dados colhidos pela observação.

\section{PALAVRAS-CHAVE}

Antropologia; Rousseau; Lévi-Strauss; Filosofia das Luzes.

\begin{abstract}
Rousseau's exhortation to take a distance vision, to observe the differences between men in order to know the specificity and the property of each man - which was expressed two centuries before Lévi-Strauss - sets what it might name rousseauist anthropology. The knowledge of man is not obtained by looking to the side and taking any type immediately available as a reference. On the contrary, it is necessary of travels ruled, an education of the look and the organization of data collected by observation.
\end{abstract}

\section{KEY WORDS}

Anthropology; Rousseau; Lévi-Strauss; Philosophy of Enlightenment. 
Rousseau diagnostica no Emílio certo fiasco das "pesquisas sobre a história natural do gênero humano" (Rousseau, I969, p. 83I). Com isso, ele retoma a primeira frase do prefácio do Discurso sobre a desigualdade que já chamava a atenção do leitor para a contradição entre a centralidade da antropologia e do conhecimento acerca do homem e seus parcos desenvolvimentos: "o mais útil e o menos avançado de todos os conhecimentos humanos me parece ser aquele do homem" (id., 1964, p. I22). ${ }^{1} \mathrm{Uma}$ nota deste escrito reproduz uma passagem do capítulo Da natureza do homem, segundo volume da História natural (I749). Nela, Buffon escreveu: "qualquer que seja o interesse que tenhamos em conhecer a nós mesmos, não sei se não conhecemos melhor tudo o que nos é estranho" (Buffon, 2008, p. 45I). ${ }^{2}$ Assim como o senhor de Montbard, o cidadáo de Genebra constata que o estágio de desenvolvimento da ciência do homem está aquém dos demais sistemas de conhecimentos. Cabe, então, explicitar as razóes desse atraso da antropologia em relação aos outros ramos do saber e quais foram os caminhos vislumbrados para melhor conduzi-la.

As viagens e a educaçáo do olhar a elas associada constituem o mote principal deste artigo. Uma nova forma de olhar que ultrapassa os limites estreitos no interior dos quais geralmente o homem foi pensado, ampliando e alargando o horizonte de investigação sobre o humano. Trata-se, então, de elaborar a passagem da consideração do homem nacional ou particular de um determinado país, com seus preconceitos, hábitos e fisionomia próprios, ao homem em geral, apreendido a partir da sistematização e da comparação das diferenças e das distâncias humanas.

\section{Exortação das viagens}

As viagens exercem um papel central no saber antropológico, pois sendo a antropologia uma disciplina de campo, sua enquete não se restringe ao trabalho de gabinete. Ao contrário de Kant — que permaneceu enraizado em Königsberg —, muitos filósofos viajaram: Aristóteles saiu de Atenas, Descartes foi para a Holanda e o próprio Rousseau, por sua vez, foi para onde pôde. Poderíamos multiplicar os exemplos. No entanto, salvo raras exceçóes, as viagens nunca foram para terras distantes, tampouco tinham por objetivo a observação dos homens e de seus costumes; antes, interessavam sobretudo as riquezas dos minérios, da flora e da fauna. Em virtude dessa falta, Rousseau propóe o que constituiria as bases de um programa etnológico efetivo cujo fim seria mapear e aferir a perfectibilidade dos mais distintos seres humanos, mesmo daqueles indivíduos desprovidos de certas características como a ra-

\footnotetext{
1 As páginas da Profissão de fé são bastante esclarecedoras sobre esse ponto: "não conhecemos nem nossa natureza, nem nosso princípio ativo; mal sabemos se o homem é um ser simples ou composto; mistérios impenetráveis cercam-nos por toda parte; eles estão acima da regiāo sensível; para penetrá-los, acreditamos ter inteligência e só temos imaginação" (Rousseau, 1969, p. 568).

2 Ver a nota ir do Discours sur l'origine de l'inégalité (Rousseau, 1964, p. 195).
} 
cionalidade, a linguagem, etc. Tais carências não seriam razóes suficientes para excluir estes seres dos limites da humanidade. Assim, em tom de manifesto, o autor clama com urgência por filósofos viajantes. O texto de Rousseau, embora velho conhecido dos intérpretes, vale a pena ser lembrado por sua vitalidade e pertinência:

Suponhamos um Montesquieu, um Buffon, um Diderot, um Duclos, um d'Alembert, um Condillac ou homens dessa têmpera, viajando para instruir seus compatriotas, observando e descrevendo, como sabem fazer, a Turquia, o Egito, a Barbária, o Império do Marrocos, a Guiné, o país dos Cafres, o interior da África e suas costas orientais, os Malabares, o Mongol, os rios dos Ganges, os reinos do Sião, de Pegu e de Ava, a China, a Tartária e, sobretudo, o Japão; depois, no outro hemisfério, o México, o Peru, o Chile, as Terras Magelânicas, sem esquecer os patagóes (verdadeiros ou falsos), o Tucumã, o Paraguai — se possível —, o Brasil, enfim, as Caraíbas, a Flórida e todas as regiốes selvagens. Viagem a mais importante de todas e que seria preciso fazer com o maior cuidado. Suponhamos que esses novos Hércules, retornando de suas excursóes memoráveis, fizessem depois com vagar a história natural, moral e política do que tivessem visto, veríamos sair um mundo novo de baixo de suas penas e aprenderíamos assim a conhecer o nosso (Rousseau, 1964, p. 313).

Viagens feitas com cuidado a fim de observar e descrever outros mundos, novos mundos de homens diferentes do mundo europeu ocidental, cuja compreensão é necessária para iluminar as dinâmicas de funcionamento deste último. $\mathrm{O}$ que importa é a afirmação e a valorização das diferenças e das distâncias que, veremos adiante, são como as condiçóes prévias para a apreensão da verdadeira proximidade. Para Rousseau, o processo de constituição da humanidade é um movimento de dispersão. Numa sentença do Emílio, o autor diz que o "homem não está plantado em um país como uma árvore para aí permanecer para sempre" (id., I969, p. 266). E a dispersão implica em distinçôes entre os grupos humanos. ${ }^{3}$ Em face disso, mostra-se indispensável realizar viagens para observar o resultado das migraçóes, mapeando os seres participantes da espécie humana, aprendendo suas diferenças e propriedades.

O objetivo de Rousseau é duplo: distinguir a animalidade da humanidade e, simultaneamente, fazer uma distinção intraespecífica entre os homens, já que um grupo humano se separa e se distingue cultural e fisicamente de outros. Somente por meio de campanhas bem orientadas e da realização de comparaçóes é que o homem chegará a se conhecer verdadeiramente, a divisar seu mundo distinto da animalidade $e^{4}$ da natureza e, ao mesmo tempo, a compreender seu sistema de refe-

3 Desenvolvemos esta teoria das ondas migratórias e da diversidade humana em um artigo intitulado "Mudanças ambientais, aumento populacional e diversidade na antropologia de Rousseau", presente no livro Técnica, natureza e ética socioambiental (2019).

4 Rousseau escreve no Discurso sobre a desigualdade: "afirmo que quando tais observadores, referindo-se a um certo animal, dissessem ser um homem e de outro ser uma fera, dever-se-ia crer. Constitui uma enorme simplicidade basear-se, a esse respeito, em viajantes grosseiros, em relação aos quais se é algumas vezes tentado a fazer a mesma pergunta que eles se metem a resolver acerca de outros animais" (Rousseau, 1964, p. 214). 
rência cultural distinto dos sistemas forjados no seio de outros povos ou agrupamentos humanos. Nesses termos, o tema da viagem converte-se numa das questóes centrais da antropologia de Rousseau.

\section{Epistemologia do olhar}

Emerge ao lado do tema das viagens a questão do olhar. Na introdução de seu Ensaio (I746), Condillac havia afirmado que nós “vemos apenas ao nosso redor" e, não obstante, "acreditamos ver tudo o que é" (Condillac, 20I4, p. 6I). Mesmo fora de seu contexto original, esta frase é elucidativa para o que queremos ressaltar, pois resume o problema colocado por Rousseau. O erro apontado é o etnocentrismo, isto é, o observador acreditar na possibilidade de "julgar o gênero humano", mesmo tendo tomado como ponto de partida uma má definição (contaminada ou parcial) de homem; diz respeito à cegueira e surdez do homem, particularmente do homem europeu, à sua incapacidade de se despir de seus costumes para ver e ouvir o outro e, deste modo, considerar o mundo para além das fronteiras nacionais que o encerram.

Sobre música e etnocentrismo, o Ensaio sobre a origem das linguas sustenta que a materialidade e o aspecto físico dos sons sáo experimentados por todos os homens, mas que cada um deles os prova de uma maneira distinta, a ponto de uma mesma música ser capaz de produzir efeitos bem diferentes nas pessoas. Rousseau insiste que o prazer do ouvido é obra do hábito e do costume: não adianta imaginar um som universalmente reconhecido e aprazível que possa proporcionar em todas as pessoas os mesmos efeitos, sentimentos e paixóes. Por oposição a uma impressão física meramente sensível, uma impressão moral só é determinada em um sistema cultural. Assim sendo, se a Europa detesta a música não europeia, não é de surpreender que os povos ditos bárbaros não tenham muito apreço pela música ocidental: os europeus são "tão sensíveis a impressões que são nulas aos bárbaros" e as músicas europeias "mais tocantes não são mais que um vão ruído para o ouvido de um caraíba” (Rousseau, I995, p. 418). ${ }^{5}$

Apesar de reconhecer a importância da música para a crítica ao etnocentrismo, focaremos nossa análise no papel da visão e do olhar. Dito isto, embora Rousseau afirme no Ensaio que "todas as riquezas do colorido expóem-se ao mesmo tempo sobre a face da Terra” e que, portanto, com um só olhar já se terá visto tudo o que

\footnotetext{
5 Contrário à perspectiva de encarar a harmonia enquanto algo natural, dado pela natureza, Rousseau considera que ela possui apenas belezas de convençáo e jamais agradaria ouvidos que náo se instruíram a seu respeito. Neste sentido, ela não pode ser universalizada. Como bom discípulo de Condillac, o autor pretende mostrar que houve uma apariçáo histórica da harmonia, em um determinado período e em um lugar bastante preciso. Portanto, somente pelo hábito será possível senti-la e saboreá-la; somente um ouvido cultivado será capaz de apreendê-la. Rousseau não sugere aqui que as consonâncias não existam na natureza, mas simplesmente que elas não aparecem como tais na experiência primitiva. No Princípio da melodia e no Exame dos dois princípios desenvolvidos por Rameau, Rousseau assevera: "embora o princípio de harmonia seja natural, como ele se oferece ao sentido somente sob a aparência do uníssono, o sentimento que o desenvolve é adquirido e fabricado" (Rousseau, 1987, p. 447; 1995, p. 355).
} 
o objeto é capaz de oferecer (ibid., p. 419), devemos reconhecer a inevitabilidade de se educar os olhos, de modo a ensiná-los a ver. Somente com uma educação do olhar seremos capazes de bem definir os conceitos de homem e de natureza humana e, dessa maneira, compreender que nem a linguagem nem a razão, ou ainda, nenhum dos caracteres secundários e adquiridos constituem, em hipótese alguma, as marcas que definem de forma definitiva a humanidade.

Tal como Cheselden - que havia, em I728, extraído as cataratas de um jovem cego de nascença, recuperando-lhe a visão - , convém desobstruir o olhar culturalmente viciado do observador. E ainda - para dar sequência ao paralelo com a teoria do conhecimento da época, a metafísica de chave empirista - , do mesmo modo que o tato auxilia ou ensina o olho a ver, educando-o (tal como defendem Locke, Buffon, Condillac ${ }^{6}$, o próprio Rousseau e tantos outros), é preciso ensinar o observador a enxergar. "Com os melhores olhos, o homem mais clarividente nada veria se não tivesse aprendido a ver desde a infância", diz Rousseau no Tratado de esfera (I995, p. 585). Ao longo dos livros II e III do Emílio, o autor pretende mostrar que o olho, ou melhor, a visão, não é algo dado de imediato, pelo contrário, trata-se antes de uma construção e que, assim sendo, é preciso aprender a ver. Em outros momentos do próprio Emílio (livros IV e V) e de outros textos de Rousseau, há um esforço metodológico em aprender e ensinar a ver os outros seres humanos, o que acaba por sugerir, como bem notou Martin Rueff, uma continuidade entre estes dois movimentos do texto (Rueff, 2003, p. 204). Assim, se é preciso aprender a se servir da visão e ensinar o olho a ver, é igualmente necessário capacitá-lo para observar e apreender as diferenças existentes entre os homens, já que o próprio do ser humano não é apreendido em um sentido estável, mas ocupa um lugar de disputa no qual múltiplas formas podem ser admitidas. Portanto, a educação do olhar possui um estatuto ao mesmo tempo epistemológico e antropológico; o processo epistemológico de construção do olhar é, então, coextensivo ao esforço antropológico.

Ao longo do século XVIII consolidou-se a ideia de que não é preciso somente ver, mas ver de modo diferente. ${ }^{7}$ Pode-se mesmo considerar, partindo das reflexóes de Foucault, o nascimento nos séculos XVII e XVIII (na idade clássica) de uma nova epistemologia do olhar, com inéditas formas de observação ${ }^{8}$. E não à toa Micrômegas foi escrito nesse período (1752). Em todo o movimento de constituição epistemológico e no que diz respeito particularmente às viagens, trata-se menos de uma lista

\footnotetext{
6 Se isso é verdade para o Tratado das sensaçôes (I754), não o é para o Ensaio (I746).

7 Ver o artigo de Blanckaert (2009), "Le fait et la valeur: disciplines de l'observation dans les instructions ethnographiques (XVIIIe-XIXe siècle)".

8 Foucault fala de um "campo novo de visibilidade que se constituiu em toda a sua espessura" (Foucault, 1999, p. I8I). Ver todo o quinto capítulo do livro As palavras e as coisas ("Classificar") e também a introdução do Nascimento da clínica (Foucault, I998, p. VII-XVIII). Martin Rueff fala de uma "arqueologia do olhar, do homem vendo, de sua relação com o visível" (Rueff, 2003, p. 198).
} 
de objetos a descrever do que de uma educação do olhar. Nestes termos, não é simples viajar. É necessário bem observar e estar munido de um método.

A transformação do olhar investigativo se faz também ver em Rousseau. Vejamos, então, como as questóes das viagens e do olhar aparecem ao longo do Discurso sobre a desigualdade, do Emílio e do Ensaio.

A cada rincão o observador ofereceria apenas a descrição de si próprio ou, como diria Condillac, do que estivesse ao seu redor, isso é o que dizem tais textos de forma sumária. Não há abertura para a diferença e o objeto de atração do olhar é sempre o mesmo, o idêntico, o próximo. Anula-se o outro enquanto tal, já que o observador força uma identificação dessa alteridade consigo mesmo e com seu sistema cultural. Um francês - mas poderia ser qualquer outra nacionalidade — não reconheceria a humanidade de outro ser humano que não trajasse os hábitos franceses (Rousseau, I96I, p. I2). No máximo, ele reconheceria - ou melhor, acreditaria reconhecer esses hábitos em alguém que definitivamente não os possui. Entre a falta e a ilusão constroem-se imagens que revelam mais dos franceses, sua cultura ou hábitos, que daqueles que cruzaram com o seu olhar.

\section{0 problema oftalmológico: de perto e de longe}

Para melhor compreender o apagamento ou embotamento das diferenças é preciso atentar para o princípio antropológico presente nos escritos de Rousseau. Seus contornos são apresentados em um pequeno texto intitulado Ideia de método na composição de um livro. Nele, Rousseau diz que não convém estudar o "espírito humano considerado em si mesmo e tomado como indivíduo". Antes, é indispensável "examinar o homem por suas relações" (Rousseau, 1964, p. I244). Tal princípio é posteriormente retomado no Emílio nos seguintes termos: o estudo conveniente ao homem é o estudo do homem por meio de suas relaçôes (id., I969, p. 493). E também na Nova Heloisa: "meu objetivo é conhecer o homem e meu método é estudá-lo em suas diversas relaçôes" (id., I96I, p. 242). Este princípio metodológico - mobilizado para criticar o etnocentrismo, a ignorância das diferenças e a cegueira para as relações - é claramente exposto no Ensaio sobre a origem das línguas:

Para bem apreciar as açóes dos homens, é preciso tomá-las em todas as suas relações, e é isso que jamais nos ensinam a fazer. Quando nos colocamos no lugar dos outros, é sempre como se nós fôssemos modificados, não como se eles devessem sê-lo, e quando pensamos julgá-los segundo a razáo, apenas comparamos seus preconceitos com os nossos (Rousseau, I995, p. 409).

Ao mesmo tempo que se anuncia o princípio basilar da investigação antropológica, vemos também nessa passagem a inscrição de seu apagamento ou esquecimento. Em suma, as limitaçóes do campo de visão provocam a reduçáo das especificidades dos outros povos e, por conseguinte, impóem a impossibilidade de se re- 
conhecer a alteridade em sua diferença, impedem maiores voos aos estudos do homem e, por fim, acarretam erros incontornáveis no que diz respeito à natureza e à condição humanas.

São muitas as imagens que afirmam um vício oftalmológico cultural na forma como os observadores enxergam os fatos relativos ao homem e à humanidade. $\mathrm{Na}$ nota X do segundo Discurso, Rousseau afirma - numa passagem que guarda algumas semelhanças com a introduçáo do Ensaio de Condillac - que a diversidade humana pode "surpreender apenas aqueles que estão acostumados a olhar tâo somente os objetos que os rodeiam e que ignoram os poderosos efeitos da diversidade dos climas, do ar, dos alimentos, da maneira de viver, dos hábitos em geral" (id., 1964, p. 208). Poucas páginas depois, lemos que os traços nacionais apenas "tocam os olhos feitos para ver" (ibid., p. 2I2).

É comum encontrar no corpus rousseauniano formulaçóes análogas a essas citadas. Tal é o caso de uma das respostas que Rousseau escreveu às Objeçôes de CharlesGeorges Le Roy. ${ }^{9}$ A objeção refere-se, particularmente, mas não exclusivamente, às notas IV e V do segundo Discurso. Para Le Roy, os homens se alimentariam apenas durante alguns meses do ano caso fossem vegetarianos-frugívoros e desprovidos do senso da previdência (tal como os homens hipotéticos imaginados por Rousseau):

É verdade que a terra abandonada a si mesma é muito fértil; mas o que concluir? Não é menos certo que o homem, fosse ele frugívoro e errante, morreria de fome durante cinco ou seis meses do ano. Os frutos farináceos, como a avelá, a castanha, etc., são os que se conservam por mais tempo; mas tudo isso, quando desprovido de um minucioso cuidado, apodrece ou germina em abril. Então seria necessário admitir acumulaçóes e uma habitação fixa. Não existem animais unicamente frugívoros senão os que podem pastar e se alimentar dos brotos ou de cascas de árvore. Os javalis que geralmente vivem de raízes, de avelâ, etc. são levados na primavera a devorar jovens animais, coelhos, etc. É preciso admitir que em muitos aspectos nos assemelhamos aos javalis (Le Roy, apud Rousseau, 1967, p. 423, apêndice 172).

A tréplica de Rousseau a essa crítica, levantada por ocasião do aparecimento do segundo Discurso e, principalmente, devido à defesa (em nota) de um regime vegetariano, é a seguinte:

Não sei em que concerne essa semelhança, tampouco sei a razão pela qual o homem, carente de frutos, deixaria de servir-se da relva, de brotos, bem como de servir-se de suas mãos ou de suas garras para desenterrar as raízes, como muitas vezes fizeram muitos dos nossos em lugares desertos. Ademais, sempre me citam os longos invernos e não querem atentar que sobre mais da metade da terra quase não há inverno, que as árvores não se desfolham e que durante todo o ano dão frutos. As razóes que me opóem são sempre tiradas de Paris,

\footnotetext{
${ }^{9}$ As objeçôes de Le Roy sobre as notas do Discurso sobre a desigualdade foram feitas em 1756 e transmitidas a Rousseau por intermédio de Condillac, em 7 de setembro de 1756.
} 
de Londres ou de algum outro pequeno canto do mundo; eu procuro apenas tirar as minhas do próprio mundo. (Rousseau, 1967, p. 424, grifo nosso)

Poderíamos citar muitas outras passagens. Contentamo-nos com uma do Ensaio sobre a origem das línguas, cuja semelhança com a tréplica a Le Roy nos salta aos olhos:

O grande defeito dos europeus consiste em sempre filosofar sobre as origens das coisas próximo ao que se passa ao seu redor. Nunca deixam de nos mostrar os primeiros homens, habitando uma terra ingrata e rude, morrendo de frio e de fome, impelidos a conseguirem um abrigo e roupas; veem em todos os lugares apenas a neve e os gelos da Europa, sem pensar que a espécie humana, como todas as outras, nasceu nas regiốes quentes e que sobre dois terços do globo o inverno mal é conhecido (id., I995, p. 394, grifo nosso).

Todas estas passagens indicam a necessidade de se alargar o campo de observaçáo e de visão, de modo a não limitá-lo às fronteiras, realidades e preconceitos regionais ou nacionais. Ou seja, para Rousseau, o olhar do observador não deve limitar-se apenas às pessoas e aos objetos que se encontram ao seu redor ou perto de si (id., I969, p. 988), deve-se ir mais longe e distanciar-se para ver as diferenças. Tal alargamento pode iniciar-se por meio da leitura das crônicas de viagem. Rousseau é um voraz leitor deste gênero literário, ele mesmo o diz: "passei a vida lendo relatos de viagem" (ibid., p. 827). Não seria inútil lembrar o quanto tais relatos faziam sucesso no século XVIII ao oferecer aos leitores um imenso repertório de usos e costumes. A História geral das viagens (I746-I759) de Prévost contava com I6 volumes até o momento da morte de seu autor.

\section{A critica aos relatos de viagem modernos}

As informaçôes colhidas pelos viajantes modernos não são acolhidas imediatamente por Rousseau como objetos úteis à construção do estudo dos homens. Ao contrário, são na grande maioria das vezes motivo de crítica. Se Rousseau pôde ter sido considerado por Lévi-Strauss o fundador da ciência do homem foi, dentre outras coisas, por ter desenvolvido uma crítica das observações feitas pelos exploradores e viajantes. Muitos autores, aliás, questionaram a validade dos fatos apresentados nos diários de viagens (vide o exemplo de Buffon). Duchet chega a sustentar que as críticas das fontes e dos relatos eram uma regra geral na época das luzes (Duchet, I97I, p. 89).

Nos textos de Rousseau, os homens que geralmente viajam não são apresentados como os mais indicados para realizar observações, nem são os mais capazes de confeccionar bons retratos dos povos contatados. No Discurso sobre a desigualdade, o autor sustenta que as descriçóes dos povos feitas pelos viajantes traçam apenas as semelhanças e a homogeneidade em razão do ensimesmamento dos observadores modernos, incapazes de sair dos limites de sua cultura. Por esta razão, eles não se deixam afetar pela alteridade; veem sempre o mesmo no outro e sempre seu próprio 
mundo ao invés de ver o deles, de modo que as diferenças e a heterogeneidade escapavam à sua compreensão. Citemos uma passagem:

Depois de trezentos ou quatrocentos anos que os habitantes da Europa inundam as outras partes do mundo e publicam incessantemente novas narrativas de viagens e relatos, estou persuadido de que os únicos homens que conhecemos são os europeus; até parece, pelos ridículos preconceitos que não estáo extintos, mesmo entre as pessoas de letras, que cada qual, sob o pomposo nome de estudo do homem, faz apenas o dos homens de seu país. (Rousseau, 1964, p. 2I2).

Nenhum dos tipos de viajantes está interessado em compreender o ser humano: a cobiça dos mercadores, a ambição dos soldados e dos marinheiros e o proselitismo dos missionários desacreditam suas narrativas de viagens. Por conta das peculiaridades e dos objetivos de seus respectivos afazeres, nenhum deles se preocupa verdadeiramente com o estudo científico, tampouco com a história natural do homem. ${ }^{10}$ Estes viajantes deixam escapar os objetos de interesse propriamente antropológicos: as idiossincrasias dos costumes, as diferenças dos modos de vida e os traços mais característicos de cada povo. Quando muito, descrevem em tom anedótico apenas os aspectos mais visíveis e triviais da constituição dos homens. Nas palavras de Rousseau, "essas pessoas, que descreveram tantas coisas, só disseram o que todos já sabiam, só souberam perceber, no outro extremo do mundo, o que poderiam notar sem sair de sua rua" (ibid.). Os relatos incidem sobre os aspectos mais aparentes e não sobre as diferenças mais profundas. Diante do outro se olhou sempre para si mesmo e, dessa maneira, formou-se uma falsa imagem: a ilusão de fixidez e de imutabilidade da natureza humana. Para eles, os homens são todos iguais e dotados todos dos mesmos predicados.

Daí veio esse belo adágio de moral, tão retomado pela turba filosofesca, que os homens são os mesmos em toda parte e que, tendo em toda parte as mesmas paixões e os mesmos vícios, é bem inútil procurar caracterizar os diferentes povos; o que é quase tão bem razoável quanto se disséssemos que não se poderia distinguir Pedro de João, pois ambos têm um nariz, uma boca e dois olhos (ibid., p. 2I2).

A crítica ao etnocentrismo europeu encontra continuidade na crítica direcionada aos objetos que atraíram a atenção dos observadores. No seu Discurso, Rousseau reconhece e até enaltece os poucos entusiastas e curiosos que empreenderam ou financiaram certas viagens tendo em vista desvendar os segredos da Terra. Todavia,

\footnotetext{
10 "Ora, não se deve esperar muito que as três primeiras classes [mercadores, soldados e marinheiros] forneçam bons observadores e, quanto aos da quarta, ocupados com a vocação sublime que os chama, ainda que não estivessem sujeitos a preconceitos próprios de seu estado como todos os outros, deve-se crer que náo se entregariam de bom grado a pesquisas que parecem mera curiosidade e que os desviariam dos trabalhos mais importantes a que se destinam. Aliás, para pregar utilmente o Evangelho, basta o zelo, e Deus dá o resto; mas, para estudar os homens, são necessários talentos que Deus não promete dar a ninguém e que nem sempre os santos possuem" (ibid.).
} 
questiona o fato de que os objetos de estudos que atraíram a atenção desses pesquisadores foram somente aqueles do mundo físico-natural (o reino mineral, a fauna e a flora). Interessado mais nos costumes e menos na descrição dos objetos, o genebrino lamenta que se tenha prestado mais atenção na zoologia, na botânica e na diversidade mineral do que na vida dos homens. Mal consigo conceber, escreve o autor, "como, num século em que se vangloriam de belos conhecimentos, não haja dois homens bem unidos, ricos, um de dinheiro, o outro de gênio", a fim de realizar "uma célebre viagem ao redor do mundo, para estudar, não mais as pedras e plantas, mas pelo menos uma vez os homens e os costumes e que, depois de tantos séculos empregados em medir e considerar a casa, atentem em, por fim, querer conhecerlhe os habitantes" (ibid., p. 213). Não se trata aqui de acabar com um tipo de estudo, o estudo do mundo físico, mas sim mostrar sua limitação e incorreção, quando exclusivo. Devemos aos observadores que se debruçaram sobre o mundo físico as primeiras enquetes a respeito dos terrenos, sem as quais não existiria ciência etnológica possível - pelo menos não em uma chave rousseauísta, segundo a qual a importância do terreno e do meio ambiente é essencial para o estudo dos homens. No entanto, se estas enquetes constituem o preâmbulo obrigatório para todo e qualquer estudo etnológico, elas não são suficientes para fundar um método científico ou filosófico que se proponha a estudar o homem e suas relaçóes com o mundo moral. Para fundar uma antropologia, é fundamental passar da simples localização geográfica, da mera menção anedótica ou do inventário dos aspectos naturais a um conhecimento mais preciso sobre os diversos povos que habitam a Terra, bem como sobre os processos que promovem as distinçōes.

Da mesma maneira que no segundo Discurso, os viajantes modernos são criticados no Emílio por conta da ausência de critérios claros e objetivos em suas observaçôes e comentários. No livro V do Emílio, Rousseau dedica toda uma seção às viagens. Tal seção apresenta um conjunto de reflexôes muito próximo aos desenvolvimentos que, anos antes, fizeram sua aparição na nota $\mathrm{X}$ do segundo Discurso. Por esta razão, constitui tarefa fundamental comparar e colocar esta parte do Emílio ao lado do segundo Discurso e dos capítulos VIII à XI do Ensaio, já que ela é igualmente relevante para a construção da teoria do homem ou da antropologia de Rousseau.

Nessa seção, Rousseau diz não ter encontrado dois relatos que lhe "tenham dado a mesma ideia do mesmo povo". É bastante reveladora a sentença expressa: "não é preciso ler, é preciso ver" (Rousseau, 1969, p. 827). De um lado, temos o "livro do mundo", passível de ser lido pelo olhar e, de outro, a frivolidade do saber livresco: "leitura em demasia serve apenas para fazer presunçosos ignorantes [...]. Tantos livros nos fazem negligenciar o livro do mundo" (ibid., p. 826). Todas estas consideraçôes sobre a leitura de relatos de viagens ou de livros científicos não surpreendem o leitor habituado com as páginas do Discurso sobre as ciências e as artes, do Discurso sobre a desigualdade ou com as críticas à escrita presentes no Ensaio sobre a origem das linguas. 
Também figura nas páginas do Emílio, é preciso dizer, uma crítica aos objetivos das viagens. Há dois tipos de viagens: "viajar para ver o país" e viajar "para ver os povos". Para Rousseau, tanto no quarto livro do Emílio (ibid., p. 493) quanto no quinto, o homem já formado não conhece da mesma maneira que uma criança. Enquanto esta última, limitada ao seu ser físico, "observa as coisas esperando" num segundo momento "observar os homens", o outro, ao contrário, por ser capaz de acessar seu ser moral, "deve começar por observar seus semelhantes e apenas depois e se tiver tempo observar as coisas". O autor ainda complementa afirmando ser a segunda forma de conhecer a mais importante àqueles que querem "filosofar" (ibid., p. 832). Desse modo, tudo se passa como se os viajantes e naturalistas do segundo Discurso agissem como crianças que meditam sobre as coisas e não sobre as relaçóes humanas, uma vez que suas descriçóes apresentam a riqueza do mundo natural (a geografia, a topografia e a variedade do mundo animal e vegetal) de um determinado lugar, contudo se detém raramente sobre os homens.

\section{A filosofia como antropologia}

Como todo observador é intimamente marcado por sua cultura, por seus interesses particulares e por sua missão, nenhum deles é capaz de observar o outro enquanto tal, nenhum deles é capaz de relativizar seu próprio lugar de observação. Por isso, as descriçôes que se almejam objetivas náo passam de pontos de vista parciais fundados em preconceitos.

O que garante que a filosofia não reproduza em seus discursos e relatos as perspectivas etnocêntricas e particulares da sociedade na qual foi formada? Certamente, dirá Rousseau, há uma filosofia preguiçosa e impaciente que reproduz os preconceitos de seu tempo. No entanto, há uma outra, a boa filosofia (antropologia), que busca ascender aos conhecimentos gerais sobre o homem. Suas análises devem ser feitas com sinceridade e método, fundadas na boa-fé, de modo que elas possam apreciar os costumes e os gêneros de vida mais afastados. É indispensável, então, despir-se dos preconceitos nacionais e entregar-se às viagens, sem outro objetivo que não seja o conhecimento do homem ou dos homens. Eis o papel e a responsabilidade da filosofia e do filósofo.

Rousseau clama por filósofos e filosofias que viajem, que saibam observar e descrever, recuperando a herança de uma tradição já perdida:

Será que um dia veremos renascer aqueles tempos felizes em que os povos não se metiam a filosofar, mas em que os Platóes, os Tales e os Pitágoras, animados por um desejo ardente de saber, empreendiam as maiores viagens unicamente para se instruir e iam longe sacudir o jugo dos preconceitos nacionais, aprender a conhecer os homens por suas conformidades e por suas diferenças, e adquirir esses conhecimentos universais que não são exclusivamente os de um século ou de um país, mas que, sendo de todos os tempos e de todos os lugares, são, por assim dizer, a ciência comum dos sábios? (ibid., p. 213). 
Até o momento, não foi esse o objetivo que mobilizou a filosofia. Na impaciência de seu método, ela acredita poder decidir suas questóes sem inventariar e sem compreender as diferenças tanto no tempo quanto no espaço e, desse modo, sempre projeta seus preconceitos (ou os do século) em seu objeto. Para Rousseau, "os particulares podem ir e vir, parece que a filosofia não viaja, de modo que a de cada povo é pouco própria para um outro" (ibid., p. 212). Duas interpretaçóes parecem aqui possíveis e náo excludentes: I) o texto tomado em seu conjunto deixa supor que os filósofos deveriam viajar mais para, com isso, dar voz às narrativas feitas não a partir de interesses comerciais e de conquista, e sim a partir do interesse em estudar e desvendar a história natural do homem; 2) a filosofia dos viajantes se mantém enraizada em seu país de origem, entranhada em uma visáo de mundo autocentrada, sendo, portanto, a expressão de um sistema cultural particular de determinado povo, sem qualquer relação com o conhecimento universal sobre o homem.

A oposição apresentada no Emílio entre livro do mundo e saber livresco guia até certo ponto a crítica de Rousseau. O francês é apresentado como o povo que mais lê ou, ao menos, a França é figurada como o país no qual mais se imprime e se publica relatos de viagens. Náo se segue que esse povo seja o que mais conhece o gênio e os costumes das demais naçóes. Trata-se do exato oposto. Na sequência, vemos que o francês também é o que mais viaja e, por conseguinte, o que mais vê. Curiosamente, não se segue que ele seja o que mais conhece: "cheio de seus usos, confunde tudo o que não se assemelha a eles. [... E] de todos os povos da Europa, o que mais vê é o que menos conhece" (Rousseau, I969, p. 828). De modo análogo ao que aparece no segundo Discurso no que se refere ao "pomposo" estudo do homem, vemos no Emílio que um parisiense que crê conhecer os homens, "conhece apenas os franceses" (ibid., p. 826).

Nesse sentido, não basta somente ver. A primeira oposição (ver e ler) incorpora no interior do primeiro de seus termos uma segunda, envolvendo ver e conhecer. Esta oposição vem precisar a primeira: de um lado, encontra-se a errância sem objetivo e, de outro, a viagem regrada. "Tudo que se faz por razão deve ter suas regras. As viagens, consideradas como parte da educação, devem ter as suas. Viajar por viajar é errar, é ser vagabundo" (ibid., p. 832). Fundamentalmente, "é preciso estabelecer regras" (ibid., p. 837) e guias para as observaçôes, não sendo suficiente percorrer a esmo os países a fim de se instruir. Por isso a ideia de uma educação e correção do olhar. "É preciso saber viajar"; "para observar é preciso ter olhos, e direcioná-los aos objetos que se quer conhecer". Para o autor, seria um golpe de muita sorte ver exatamente o que náo se procurou olhar (ibid., p. 828). Segue-se disso tudo que sem o auxílio de princípios orientadores não se faz propriamente observações adequadas, e a seção sobre as viagens do Emílio tem justamente por objetivo definir as regras das viagens e constituir quais seriam seus princípios metodológicos.

A ideia central da seção sobre as viagens se faz ver na oposição entre, de um lado, o homem nacional ou particular de um determinado país com seus costumes, hábitos 
e fisionomia e, de outro, os homens em geral — oposição que guarda certas analogias com a que aparece no segundo Discurso entre uma filosofia preguiçosa e impaciente e a boa filosofia. Para Rousseau, mesmo se os observadores lessem ou fossem capazes de ler o livro do mundo, eles não divisariam senão "sua folha" (ibid., p. 826) — os supracitados exemplos do francês e da filosofia são, sobre isso, reveladores. Em outras palavras, mergulhados nesse imenso álbum de fotografias, eles se ateriam apenas aos seus respectivos retratos particulares e, dotados dessa espécie de negativo, tentariam revelar a imagem dos demais povos na esperança de refletirem a mesma cultura. Estas imagens e fotografias, no entanto, sairiam bastante distorcidas: eles náo veriam senão aquilo que seus preconceitos nacionais lhes permitem ver. Nesses termos, o projeto de universalidade apareceria apenas "como ideológico, prática antropofágica de uma consciência singular ou de uma certa cultura" (Prado Jr., 2008, p. 317). O que se afirma através desta aparente vontade de universalidade seria antes a particularidade de uma consciência histórica e local, sendo toda humanidade local.

Em contraste, temos o homem ou "homens em geral" (Rousseau, I969, p. 827), náo reduzidos a uma variedade cultural particular. Apenas viagens bem conduzidas são capazes de oferecer sua imagem. $\mathrm{O}$ viajante deve, então, ser capaz de avaliar e comparar o que ele observa - uma vez que, para Rousseau, aquele que nada comparou ou que viu apenas "um povo, em vez de conhecer os homens, conhece apenas as pessoas com as quais viveu" (ibid.). Parafraseando a fórmula canônica do Ensaio, podemos dizer que viajar não significa senão observar as diferenças para comparálas e, então, conhecer as propriedades. Viajar é um meio para acessar o conhecimento geral sobre o ser humano, o homem abstrato e indeterminado, irredutível a formas fixas, a um grupo ou a uma cultura particulares. A universalidade, se existir, encontra-se somente no sistema das diferenças.

Desta feita, seria preciso percorrer toda a Terra para estudar o homem? Ou ainda, para conhecer a espécie humana seria necessário conhecer todos os indivíduos? Não necessariamente. Para Rousseau, uma amostra social de alguns povos já é suficiente para que se possa acessar esse conhecimento. "Quem viu dez franceses, viuos todos". Cada nação "tem seu caractere próprio e específico, apreendido por indução, náo de um só de seus membros, mas de vários". Segue-se que "aquele que comparou dez povos conhece os homens, tal como aquele que viu dez franceses conhece os franceses" (ibid., p. 827). Em outras palavras, para guiar a história natural do homem ao grau adequado de desenvolvimento, deve-se conhecer e observar alguns homens de alguns povos, pelo menos é o sugere o autor nas páginas do Emílio.

É sabido que este livro se inscreve no âmbito de uma educação privada e que as viagens exercem um importante papel para a formaçáo do aluno. No segundo Discurso, por sua vez, o esforço parece direcionar-se propriamente para um programa de mapeamento global dos povos, já que se trata de um projeto científico que transcende aquele do Emílio. Para fundar uma verdadeira antropologia, convém em um 
primeiro momento mapear as diferenças e as variaçóes por meio de exaustivas viagens ao redor do mundo e de trabalhos bem conduzidos de pesquisas e de descriçóes dos povos existentes.

A comparação etnográfica contribui para destacar os caracteres comuns à maioria das sociedades humanas. Lemos na carta XVII da segunda parte da Nova Heloisa a seguinte passagem:

Percorria lenta e cuidadosamente várias [...] províncias, as mais distantes umas das outras; todas as diferenças que observava entre elas me davam o gênio particular de cada uma; tudo o que tinham em comum - e que os outros povos não tinham - formaria o gênio nacional; e o que se encontrava por toda parte pertenceria em geral ao homem. (Rousseau, I96I, p. 242)

O que em geral pertence a todos os homens é a liberdade e a perfectibilidade. Observar os diferentes povos significa, então, ver e elencar as manifestaçóes empíricas e históricas da perfectibilidade. O conjunto dessas observaçóes ajuda a construir um tipo que nenhuma sociedade reproduz fielmente, mas que é capaz de definir a humanidade (e seus arranjos), além de indicar as direçóes nas quais se orientarão as futuras investigações e reflexões antropológicas sobre as variedades jurídicas, linguísticas, estéticas, etc. Em resumo, a definição correta da essência humana revela-se dependente de observaçóes empíricas e etnológicas prévias que permitam, por meio da apreciação das mais sutis diferenças, uma generalização e universalização daquilo que traduz factualmente a essência do homem, a saber, ser uma criatura livre e perfectível.

Viagens e pesquisas que exigem tempo, financiamento e talentos incomuns. Um verdadeiro trabalho de etnologia realizado por homens excepcionais que não compartilham das soluçóes rápidas dos viajantes e cronistas modernos. Posteriormente, a partir das diferenças constatadas se estabelecerá a identidade e, por um processo de generalizaçóes não muito fácil de compreender (Bernardi, 2004), institui-se o conceito de homem em geral. Tal método é o único capaz de delimitar as fronteiras seguras que separam a animalidade da humanidade e também de conduzir adequadamente o estudo dos homens ou da antropologia ao seu reto caminho, transformando a filosofia em uma verdadeira fonte de conhecimentos, os "conhecimentos universais" (Rousseau, 1964, p. 213), para além das fronteiras nacionais existentes entre os homens.

Tanto no segundo Discurso quanto no Emílio, o que se almeja é um alargamento do conhecimento do homem. Para além do dado imediato de um povo, de um homem ou de uma filosofia qualquer, busca-se o conhecimento do homem em geral, exposto a todos os acidentes e a todas as condiçóes da vida. Alargar o campo de visão significa, então, conhecer essa generalidade. Como bem notou Morice,

O deslizamento metafórico do livro para a folha ou para a estampa significa, de um ponto de vista histórico, o deslizamento do geral em direção ao particular. O argumento de Rousseau é, portanto, baseado na necessidade de uma 
generalizaçáo que permita reunir as folhas dispersas do grande livro do mundo, uma generalização que realize a passagem da observação de "pessoas" à observação dos "homens em geral" (Morice, 2013, p. 132).

Este homem em geral deverá ser apreendido por meio da abstração e da comparação, num processo que guarda certas afinidades com o processo de constituição do homem do puro estado de natureza, mas que náo se reduz a ele. Neste sentido, ao contrário do que pensa Morice em seu artigo "Voyage et anthropologie dans l'Émile de Rousseau" (ibid., p. I35), não se trata simplesmente de um processo de abstraçáo obtido após o apagamento das propriedades acidentais que acompanham os indivíduos em suas existências reais. Mas sim de uma abstração capaz de expor o homem "a todos os acidentes" (Rousseau, I969, p. 252) e de associá-lo a uma multidão de relaçôes concretas.

O projeto que guia o desenvolvimento do estudo do homem não pode se reduzir ao dépouillement antropológico ou à ascese meditativa alcançada por meio da introspecção, tal como a imagem do homem do puro estado de natureza. O programa desenhado por Rousseau não se refere a uma antropologia fundada na mera operação do entendimento que subtrai os acidentes para descrever o homem. Trata-se sim de uma operação do entendimento (a faculdade de generalizar), mas de uma operação que caminha na direção contrária, isto é, uma efetiva comparação etnográfica a fim de compreender os acidentes como constitutivos das humanidades e, assim, ver quais são as possibilidades da perfectibilidade assumidas historicamente pelos mais distintos homens que habitam ou habitaram o globo terrestre. As viagens nos dão condição de pensar as formas que a humanidade pôde assumir ao longo dos tempos e de acordo com circunstâncias específicas.

\section{Identidade e diferença: a comparação etnológica}

Rousseau estabelece uma correlação entre a ideia que o homem pode fazer de si mesmo (sua identidade) e a ideia de um outro, um outro homem ou outros homens. É por meio do encontro com o outro que o homem terá condiçôes de se figurar e de se ver existir. Somente assim nasce a consciência de si do homem e a imagem de sua identidade. Nesse sentido, não há propriamente conhecimento sem comparaçôes. O Ensaio nos diz que o hábito de sempre olhar as mesmas coisas impede a comparação: "aquele que vê apenas um só objeto não pode comparar". Por isso, "sempre vendo táo somente o que estava à sua volta", não tinha condiçóes sequer de conhecer "a si próprio" (Rousseau, I995, p. 396). Somente por meio da comparação é possível escapar das ilusões e dos reflexos do eu, de sorte que conhecer o outro se torna importante para conhecer a si mesmo. Uma espécie de antinarcisismo conduz Rousseau em suas reflexóes: em sua antropologia o outro vem antes de si, sendo a alteridade constituinte do eu humano. Ao contrário do cogito cartesiano que 
diz ser possível acessar o conteúdo da subjetividade sem reconhecer o outro, Rousseau considera que é através do acesso ao outro que se é capaz de acessar a identidade de seu próprio eu.

É preciso observar e comparar as diferenças e as distâncias — não se cansa de dizer o autor do Emílio em muitos de seus escritos (sejam teóricos, romances ou de teor autobiográfico). Isto é notável nos rascunhos escritos por Rousseau para suas Confissôes: "tenho observado com frequência que, mesmo entre aqueles que mais se vangloriam de conhecer os homens, cada um conhece apenas a si próprio, se for mesmo verdade que alguém se conheça, pois como bem determinar um ser pelas unicas relaçóes que estão nele mesmo, sem compará-lo com nada?" (Rousseau, I959, p. II48, grifo nosso). De modo análogo, o conhecimento sobre um povo emerge quando da observação de outros povos e da comparação. Lemos na carta XVII da segunda parte da Nova Heloísa o seguinte: "não me propus observar os franceses; pois se o caractere das naçóes apenas pode ser determinado por suas diferenças, como eu pintaria esse caractere se ainda não conheço nenhum outro?” (id., I96I, p. 242).

Rousseau ascende ao conhecimento sobre o homem do puro estado de natureza por meio da introspecção e do recolhimento, meditando em meio a floresta de SaintGermain (id., 1959, pp. 388-389), mas, simultânea e fundamentalmente, pretende estudar o homem a partir das diversidades culturais as mais distantes - num sentido que vai muito além da mera posição geográfica. Um programa similar ao esboçado por Rousseau aparece — e isto não sem razão — nos escritos de Lévi-Strauss. De acordo com este último, as razóes que o afastaram da filosofia e o conduziram à etnologia foram as seguintes: "se se quisesse compreender o homem, era preciso evitar o isolamento da introspecção, ou contentar-se em examinar uma única sociedade a nossa". Seria preciso se debruçar "sobre as experiências culturais as mais diferentes e as mais distantes da nossa" (Lévi-Strauss; Eribon, 2005, p. IIO). Tal procedimento — a "essência e originalidade da abordagem etnológica" — é por ele definido como "o olhar distanciado" (Lévi-Strauss, 1983, p. I2), o que remete à exortação feita por Rousseau dois séculos antes: "para estudar o homem, é preciso aprender a levar sua vista ao longe; é preciso começar observando as diferenças, para descobrir as propriedades" (Rousseau, I995, p. 394). Não por outra razão, o genebrino figura na epígrafe do Olhar distanciado (1983) e anteriormente, em I955, fora aclamado por Lévi-Strauss como "o mais etnógrafo dos filósofos" (Lévi-Strauss, I957, p. 4I7). 


\section{Referências bibliográficas}

BANDERA, M. D. (20I9). "Mudanças ambientais, aumento populacional e diversidade na antropologia de Rousseau”. In: BECKER, E. et al. (Ed.), Técnica, natureza e ética socioambiental. Sáo Paulo: República do Livro/Discurso Editorial, pp. 35-52.

BERNARDI, B. (2004). "'L'art de généraliser': sur le statut de la généralité chez Rousseau". In: Charrak, A. \& Salem, J. (Eds.), Rousseau et la philosophie. Paris: Publications de la Sorbonne, pp. I55-I69.

BLANCKEART, C. (2009). "Le fait et la valeur: disciplines de l'observation dans les instructions ethnographiques (XVIIIe-XIXe siècle)". In: AlBERTAN-COPPOLA, S. (Ed.), Apprendre à porter sa vue au loin. Hommage à Michèle Duchet. Paris: ENS Éditions, pp. 29-56.

BUfFON (2008). Histoire naturelle. T. II. Paris: H. Champion.

CONDILlaC, E. (20I4). Essai sur l'origine des connaissances humaines. Paris: J. Vrin.

DuCHET, M. (1971). Anthropologie et histoire au siècle des lumières. Paris: Flammarion.

Foucault, M. (1998). O nascimento da clínica. Traduçáo de R. Machado. Rio de Janeiro: Forense Universitária.

Foucault, M. (1999). As palavras e as coisas. Tradução de S. T. Muchail. São Paulo: Martins Fontes.

LÉVI-STRauss, C. (1957). Tristes Trópicos. Tradução de W. Martins. São Paulo: Editora Anhembi.

LÉvi-STrauss, C. (1983). Le regard éloigné. Paris: Plon.

LÉVi-Strauss, C. \& Eribon, D.(2005). De perto e de longe. Tradução de L. Mello e J. Leite. São Paulo: Cosac Naify.

Morice, J. (2013). "Voyage et anthropologie dans l'Émile de Rousseau”, In: Revue de métaphysique et de morale, I, n. 77, pp. I27-I42.

Prado JR., B. (2008). A retórica de Rousseau e outros ensaios. Tradução de C. Prado. São Paulo: Cosac Naify.

Rousseau, J.-J. (1967). Correspondance Complète de Jean-Jacques Rousseau. vol. IV, R. A. Leigh (ed.). Genève: Banbury and Oxford.

RousseaU, J.-J. (1987). Du Principe de la mélodie ou réponse aux erreurs sur la musique. In: WOKLER, R., Rousseau on society, politics, music and language (Texte imprimé): an historical interpretation of his early writings. New York: Garland, pp. 436-482.

Rousseau, J.-J. (1959-1995). Cuvres Complètes de Jean-Jacques Rousseau. B. Gagnebin e M. Raymond (Eds.). Paris: Gallimard.

RuefF, M. (2003). “Apprendre à voir: l'optique dans la théorie de l'homme”, In: Rousseau et les sciences, Bensaude-Vincent; Bernardi (Ed.). Paris: L'Harmattan, pp. 193-2I4. 